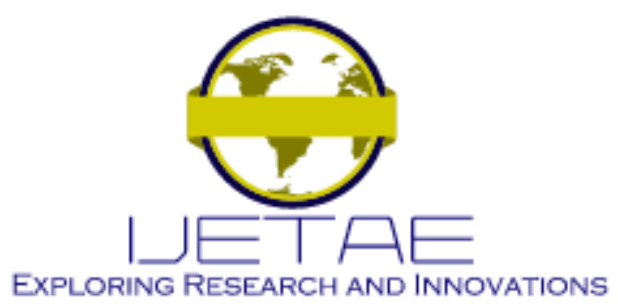

International Journal of Emerging Technology and Advanced Engineering

Website: www.ijetae.com (E-ISSN 2250-2459, Scopus Indexed, ISO 9001:2008 Certified Journal, Volume 11, Issue 10, October 2021)

Manuscript Received: 01 September 2021, Received in Revised form: 04 October 2021, Accepted: 10 October 2021

DOI: 10.46338/ijetae1021_05

\title{
Diagnostic and Prognostic Models for Predictive Maintenance: Multi-Criteria Comparative Analysis
}

\author{
Mohammed Bouaicha ${ }^{1}$, Imad El Adraoui ${ }^{2}$, Nadia Machkour ${ }^{3}$, Hassan Gziri ${ }^{4}$, Mourad Zegrari ${ }^{5}$ \\ ${ }^{1,3,5}$ Laboratory of Structural Engineering, Intelligent, and Electrical Energy (ISSIEE), The National Higher \\ School of Arts and Crafts (ENSAM), Hassan II University, Mers Sultan BP 916, Casablanca, Morocco \\ ${ }^{2,4}$ Laboratory of Engineering, Industrial Management and Innovation (IMII), The Faculty of Sciences and Technology, Hassan \\ 1 st University, PO Box 577, Settat, Morocco
}

\begin{abstract}
Predictive maintenance has evolved considerably over the past two decades making this strategy an effective way to monitor the operation of industrial systems, thereby predicting its future states and remaining lifespan. It is therefore developed through a process that begins with the collection of information from the industrial system, the objective of which is its diagnosis or / and its prognosis. This article presents an analysis of single-model and multi-model approaches to the effect of diagnostic and prognostic tasks. This analysis is based on a multi-criteria comparison of the different models in order to provide a clear vision to choose the appropriate approach for predictive maintenance. The relevance of the comparative study is argued by the development of criteria directly impacting performance, reliability, efficiency and mutual cooperation between models. Conclusions are then drawn, in order to identify the appropriate diagnostic and prognostic approach for predictive maintenance.
\end{abstract}

Keywords-Diagnostic, Efficiency, Performance criteria, Predictive maintenance, Prognostic, Reliability.

\section{INTRODUCTION}

Industry 4.0 covers a wide range of technologies, processes and systems mainly related to industrial digitization. In terms of operational scenarios, use cases in Industry 4.0 are mainly classified into three complementary areas: intelligent products, intelligent processes, and intelligent machines. These focus on the performance of industrial machines and on applications such as detecting any quality problem, predicting breakdowns, and the need for preventive maintenance. However, the most important use case of intelligent machines in terms of operations is predictive maintenance.
Predictive maintenance focuses on the organization of maintenance actions according to the actual state of health of the system, in order to provide indications whose objective is the planning of appropriate preventive interventions. It is implemented by a specific process, which can be summed up in three fundamental steps:

- Data collection: data is first collected, then stored, it undergoes pre-treatments (transformations) to prepare it for diagnostic treatment;

- Data analysis and processing: process that allows to determine the current failure mode, to locate it and to evaluate the state of health and the future performances of the system (Diagnosis) to calculate its remaining life (Prognostic);

- Decision-making: decision-making aid process which makes it possible to propose a set of alternative maintenance actions to the decision-maker.

The data analysis and processing process is crucial in a decision support approach in terms of predictive maintenance. These are two main areas: diagnosis and prognosis. It is important to emphasize that the diagnoses and prognoses are not always exclusive. However, to make a prognosis, it is necessary to carry out the diagnosis first.

The systematic review carried out by [1], whose most recent articles were consulted to identify diagnostic and prognostic patterns. Two main approaches can be extracted:

- Single-model approach: This approach exists in the form of three categories: models based on physics, on knowledge or on data;

- Multi-model approach: This approach combines at least two models among those mentioned above. 


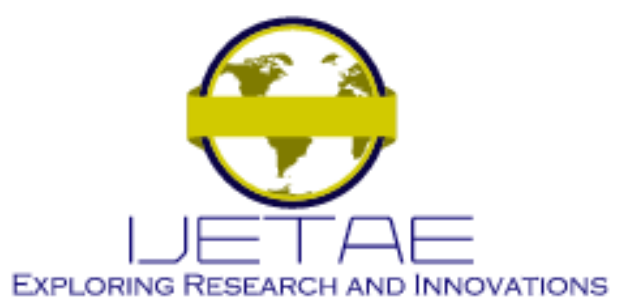

International Journal of Emerging Technology and Advanced Engineering

Website: www.ijetae.com (E-ISSN 2250-2459, Scopus Indexed, ISO 9001:2008 Certified Journal, Volume 11, Issue 10, October 2021)

\section{A. Single-model approach}

This subsection presents the unique approach methods used for diagnosis and prognosis. These models are classified into three categories:

- Knowledge-based models: This category is based on experiences that can be represented by rules, facts or cases collected during years of operation and maintenance of the industrial system. There are three types of models, those based on rules [2] or cases [3], or fuzzy models based on knowledge [4];

- Data-driven models: The data collected using the sensors is used to study component degradation, the health of the system in real time or its remaining useful life. These models are divided into three types:

- Statistical models: They aim to analyse the evolution of the variables represented by data series. These models include regression analysis, autoregressive [5], and Bayesian [6];

- Stochastic models: They design probability-based models aiming to study the temporal evolution of variables. Three main stochastic processes used, namely the Gaussian processes [7], those of Markov chains [4], and Levy model [8];

- Machine Learning Models (ML): ML is an offshoot of artificial intelligence (AI), which relies on learning algorithms to create models using data. The analysis of the literature carried out by Thyago P \& Co. [9], dealing with the themes of predictive maintenance, reveals a preference for certain machine learning methods: Random Forest RF [10], Networks of Artificial Neurons (ANN) [11, 12], Support Vector Machines (SVM) [13, 14], and $K$ means $[2,10]$.

- Physical models: They use physics equations to describe the evolution of component deterioration [15].

\section{B. Multi-modes approaches}

The results of analysis and treatment of single models for complex systems are unsatisfactory, the research referred to have generally suggested complementary models to surmount their weaknesses.

The different types of multi-model approaches can be classified into 7 groups [1]:

- Multiple knowledge-based models: This approach is rarely used in research work in the last decade;
- Multiple Data-driven models: If these models are associated, they offer for the same tasks, largely precise results as the single models;

- Multiple physical models: The equations of physical phenomena integrated in a mathematical context make it possible to improve the precision and the reliability of the diagnosis and the prognosis;

- Data-driven models combined with knowledge-based models: This architecture allows a predictive system to analyse heterogeneous data from sensors and information entered by operators or extracted from large databases using techniques exploration [16];

- Knowledge-based models combined with physical models: Studies based on this approach remain limited in research [17];

- Physical models combined with data-driven models: This approach is most prevalent in research studies of the last decade, by virtue of the reputation of data-driven models' processing capacity and their complementarity with the precision of modelling of physical models. Three main models were identified in combination with the physical models which are, the statistical models [18], the stochastic models [19], and the neural network models [20];

- Three Single Model Approaches Combined: This architecture is extremely delicate, due to its complexity and the difficulty of merging the results of each model.

C. Statistical distribution of models for diagnosis and prognosis

Table I presents the distribution of the studies consulted (2015 to 2019) between single-model and multi-model approaches for predictive maintenance, according to the systematic review of the literature carried out by J.J. Montero Jimenez \& Co. [1].

TABLE I

Distribution OF Studies FOR Diagnostics And Prognostics

\begin{tabular}{|l|l|l|}
\hline Task & Approach & Division \\
\hline \multirow{4}{*}{ Diagnostic } & Knowledge-based models & $13,3 \%$ \\
\cline { 2 - 3 } & Data-driven models & $18,9 \%$ \\
\cline { 2 - 3 } & Physical models & $1,1 \%$ \\
\cline { 2 - 3 } & Multi-model approaches & $15,6 \%$ \\
\hline \multirow{4}{*}{ Prognostic } & Knowledge-based models & $4,4 \%$ \\
\cline { 2 - 3 } & Data-driven models & $28,9 \%$ \\
\cline { 2 - 3 } & Physical models & $5,6 \%$ \\
\cline { 2 - 3 } & Multi-model approaches & $12,2 \%$ \\
\hline
\end{tabular}




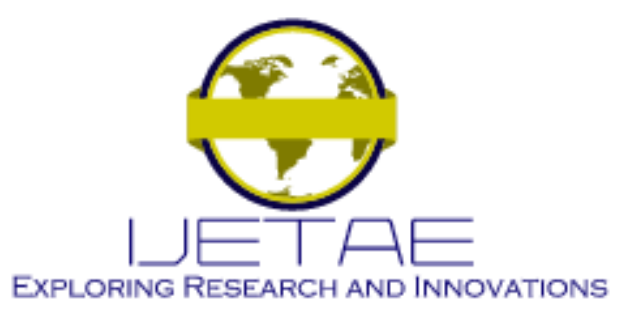

International Journal of Emerging Technology and Advanced Engineering

Website: www.ijetae.com (E-ISSN 2250-2459, Scopus Indexed, ISO 9001:2008 Certified Journal, Volume 11, Issue 10, October 2021)

\section{COMPARISON OF SINGLE MODEL APPROACHES}

We first discuss the evaluation for a possible comparison of single-model approaches according to the following criteria:

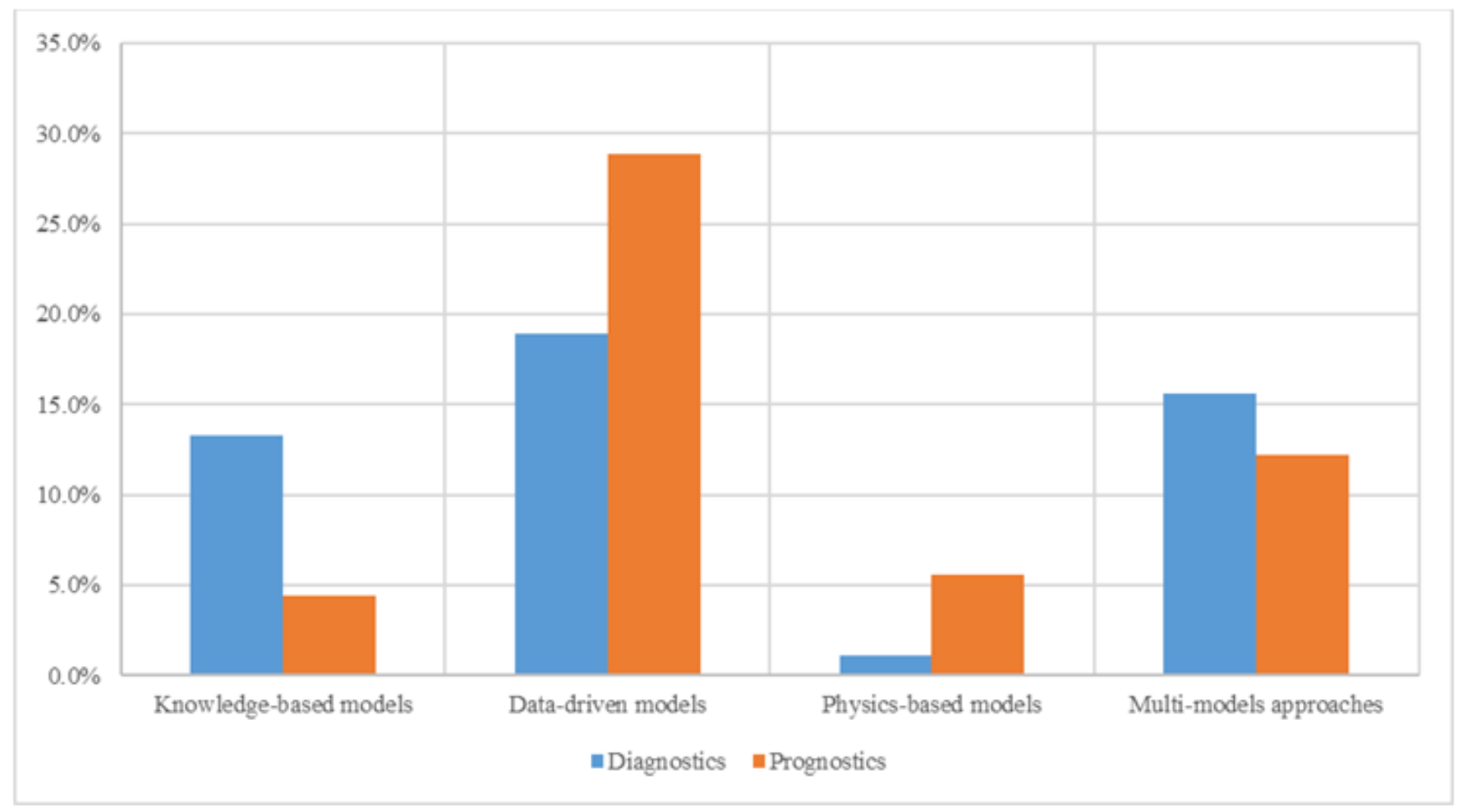

Figure 1 Distribution of studies for diagnostics and prognostics

From a quantitative and then qualitative analysis (Figure 1), we find that:

- The use of single-model approaches is used more (72.2\%) than multi-model approaches $(27.8 \%)$;

- Data-driven models make up the majority of research (47.8\%), followed by multi-model approaches $(27.8 \%)$;

- Knowledge-based models are used specifically for diagnosis, whereas physical models have been applied almost primarily to prognosis.

An analysis based on the most relevant indicators aims to perform a multi-criteria comparison between the different single-model and multi-model approaches, clearly specifying the strengths and the performance scope of each model.
- Performance: This is the set of actions that each model can perform as a diagnostic task; prognostic; diagnostic and prognostic combined with the same model; accuracy of results; possibility of implementation in multi-model approaches (prognostics); reduced computing time and explanation of the results obtained;

- Reliability: this factor is based on the ability of the model to achieve diagnostic or prognostic results or both without the need for expert knowledge, sufficient previous data, and large volume of data and management theory of the uncertainty in the data; 


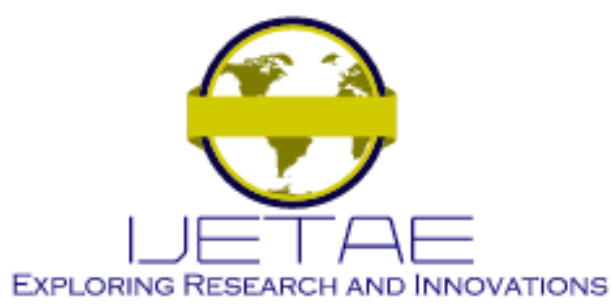

International Journal of Emerging Technology and Advanced Engineering

Website: www.ijetae.com (E-ISSN 2250-2459, Scopus Indexed, ISO 9001:2008 Certified Journal, Volume 11, Issue 10, October 2021)

- Efficiency: this factor determines the capacity of the model to be more efficient with a minimum of resources relating to computing power, mathematical knowledge, and complementary model for prognostic or Data Mining.
These evaluation criteria are determined based on the factors shown in the radar graphs of Figures 2, 3, and 4. They are mainly divided into those that have an impact on the performance of the model, its reliability and its efficiency.
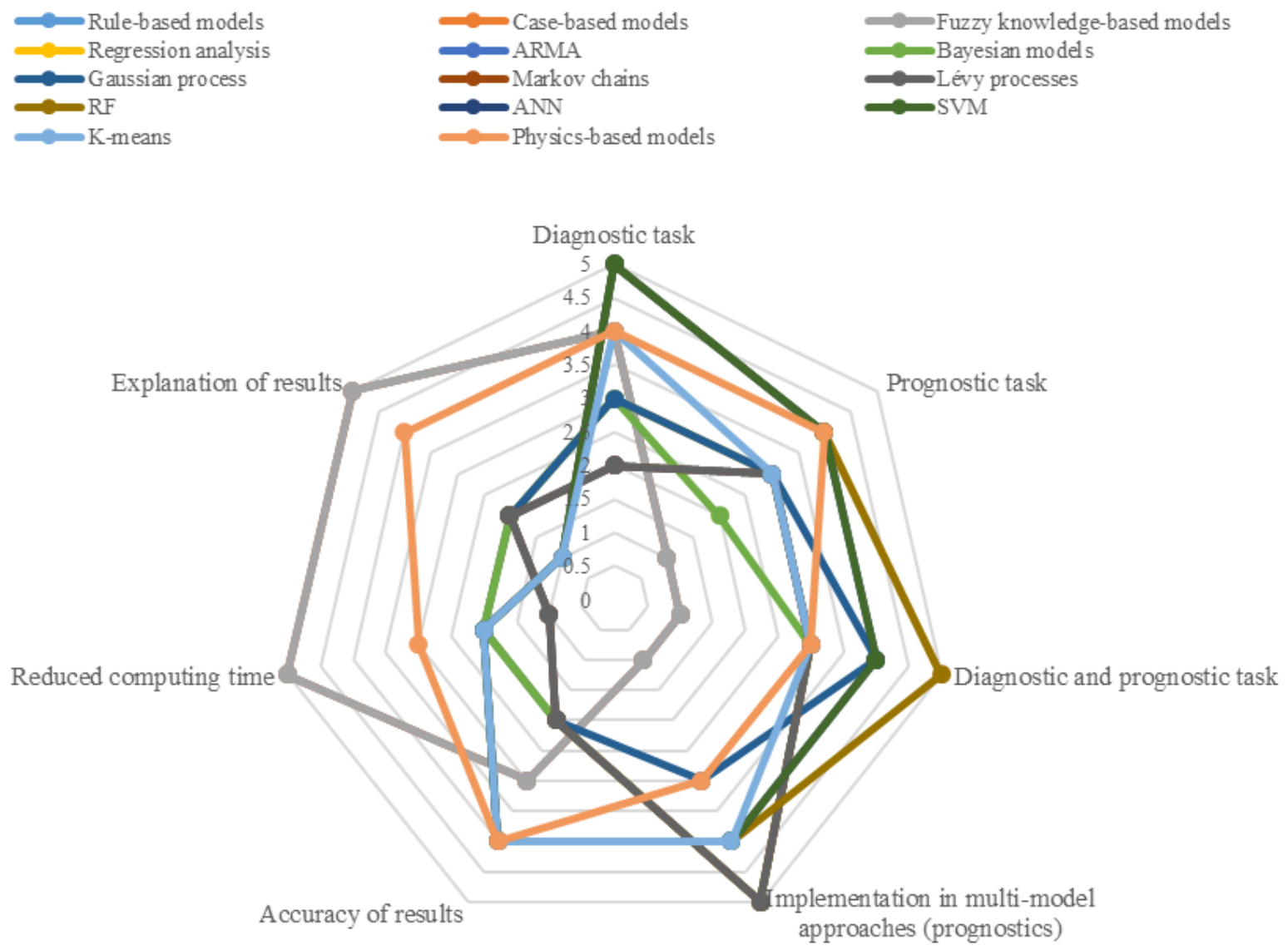

Figure 2 Factors related to the performance of single-model approaches 


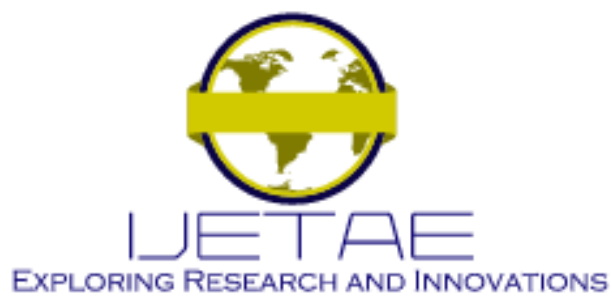

International Journal of Emerging Technology and Advanced Engineering

Website: www.ijetae.com (E-ISSN 2250-2459, Scopus Indexed, ISO 9001:2008 Certified Journal, Volume 11, Issue 10, October 2021)

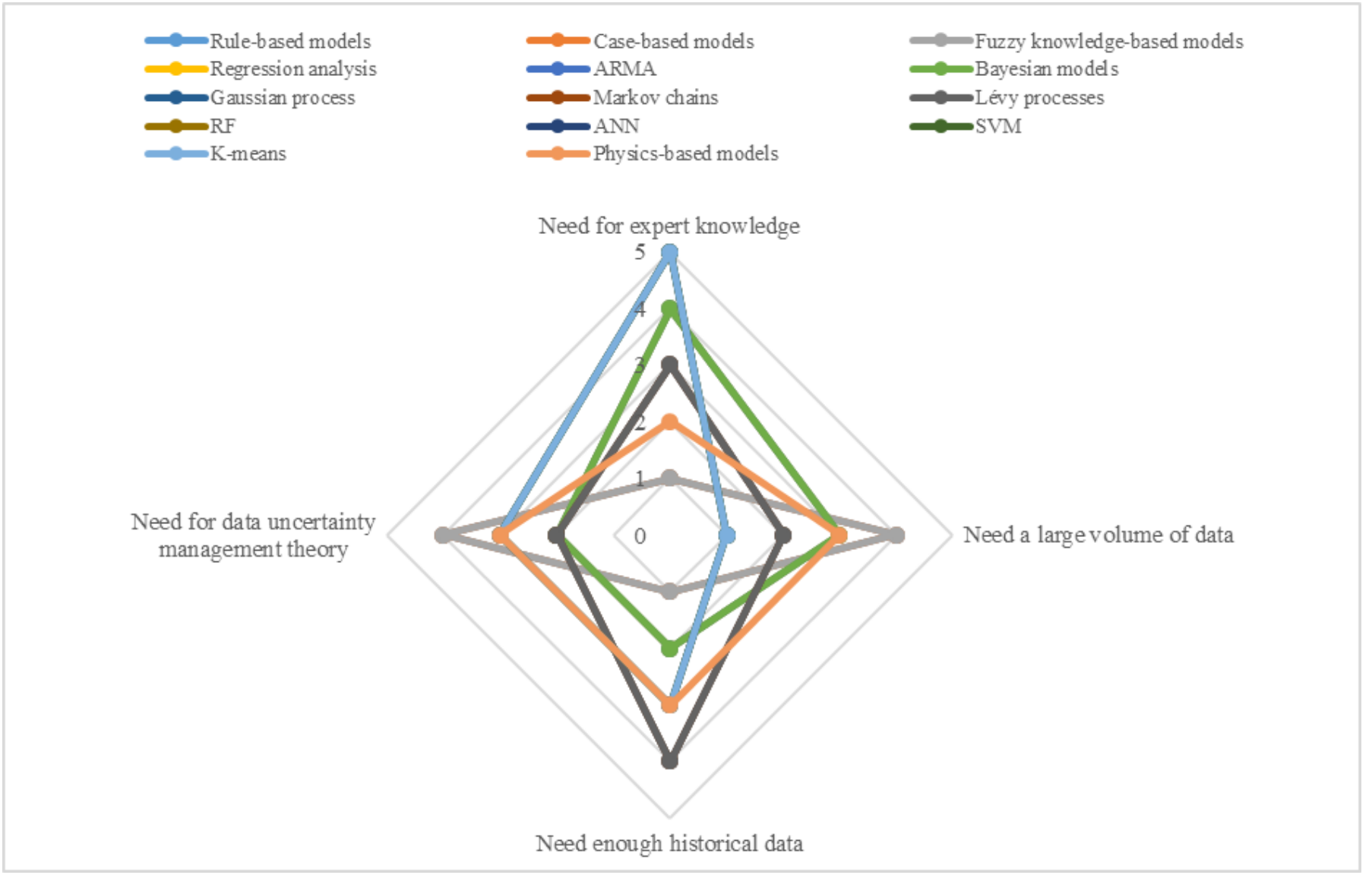

Figure 3 Factors related to the reliability of single-model approaches 


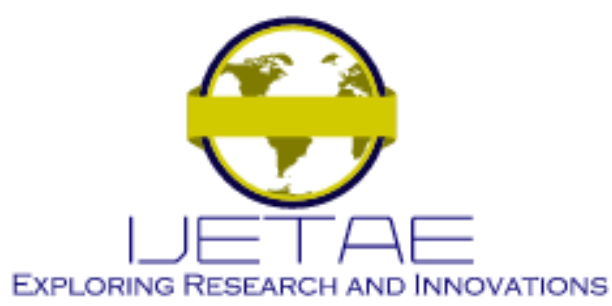

International Journal of Emerging Technology and Advanced Engineering

Website: www.ijetae.com (E-ISSN 2250-2459, Scopus Indexed, ISO 9001:2008 Certified Journal, Volume 11, Issue 10, October 2021)

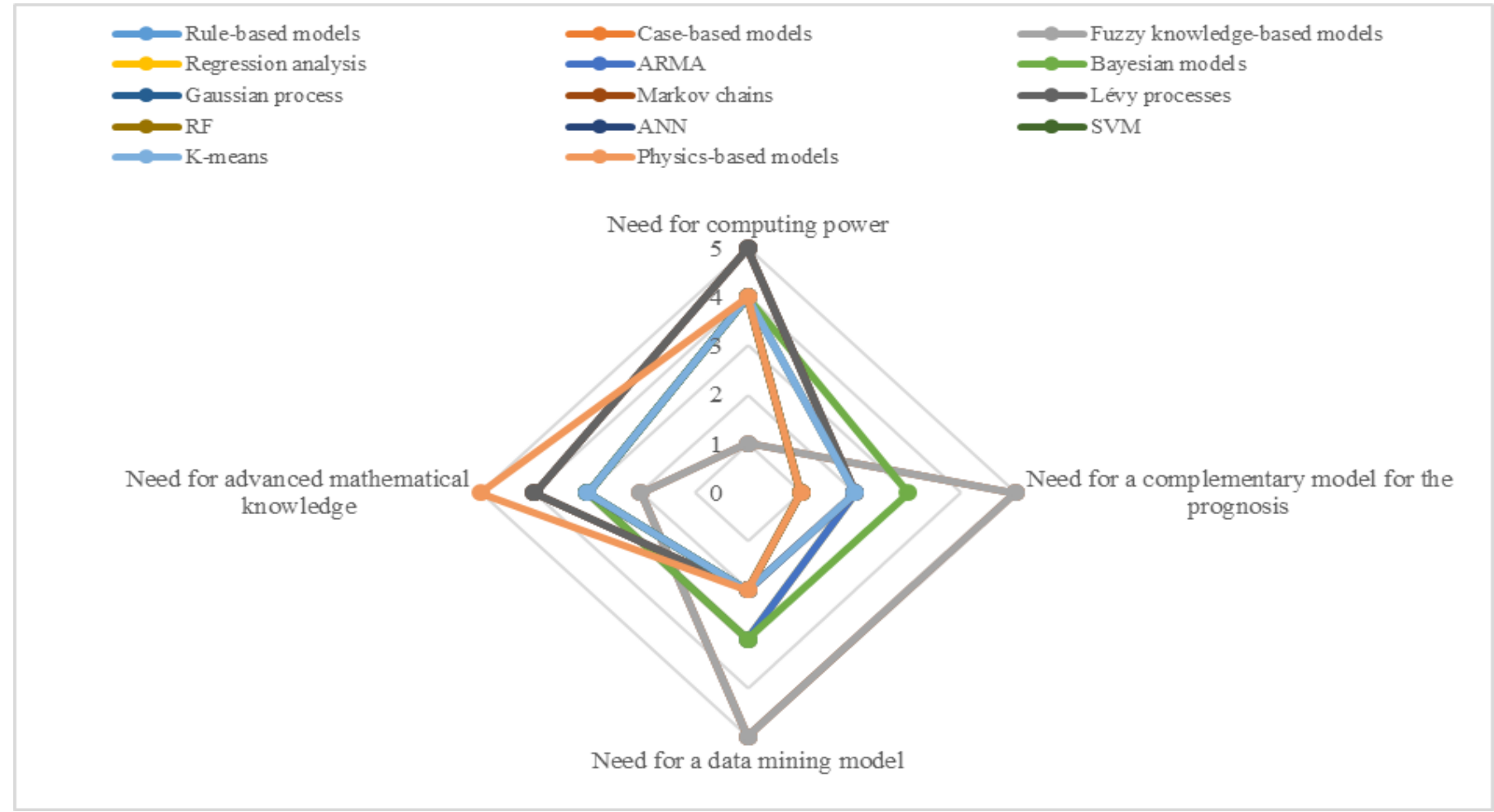

Figure 4 Factors related to the resource requirements of single-model approaches 


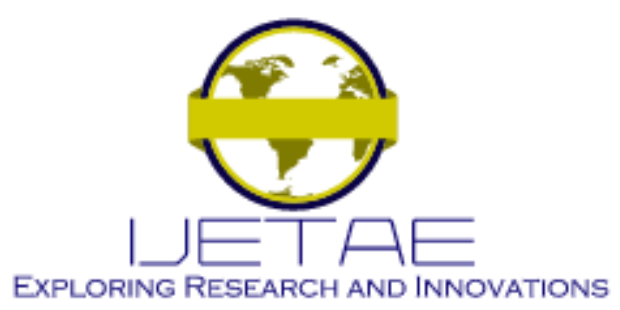

International Journal of Emerging Technology and Advanced Engineering

Website: www.ijetae.com (E-ISSN 2250-2459, Scopus Indexed, ISO 9001:2008 Certified Journal, Volume 11, Issue 10, October 2021)

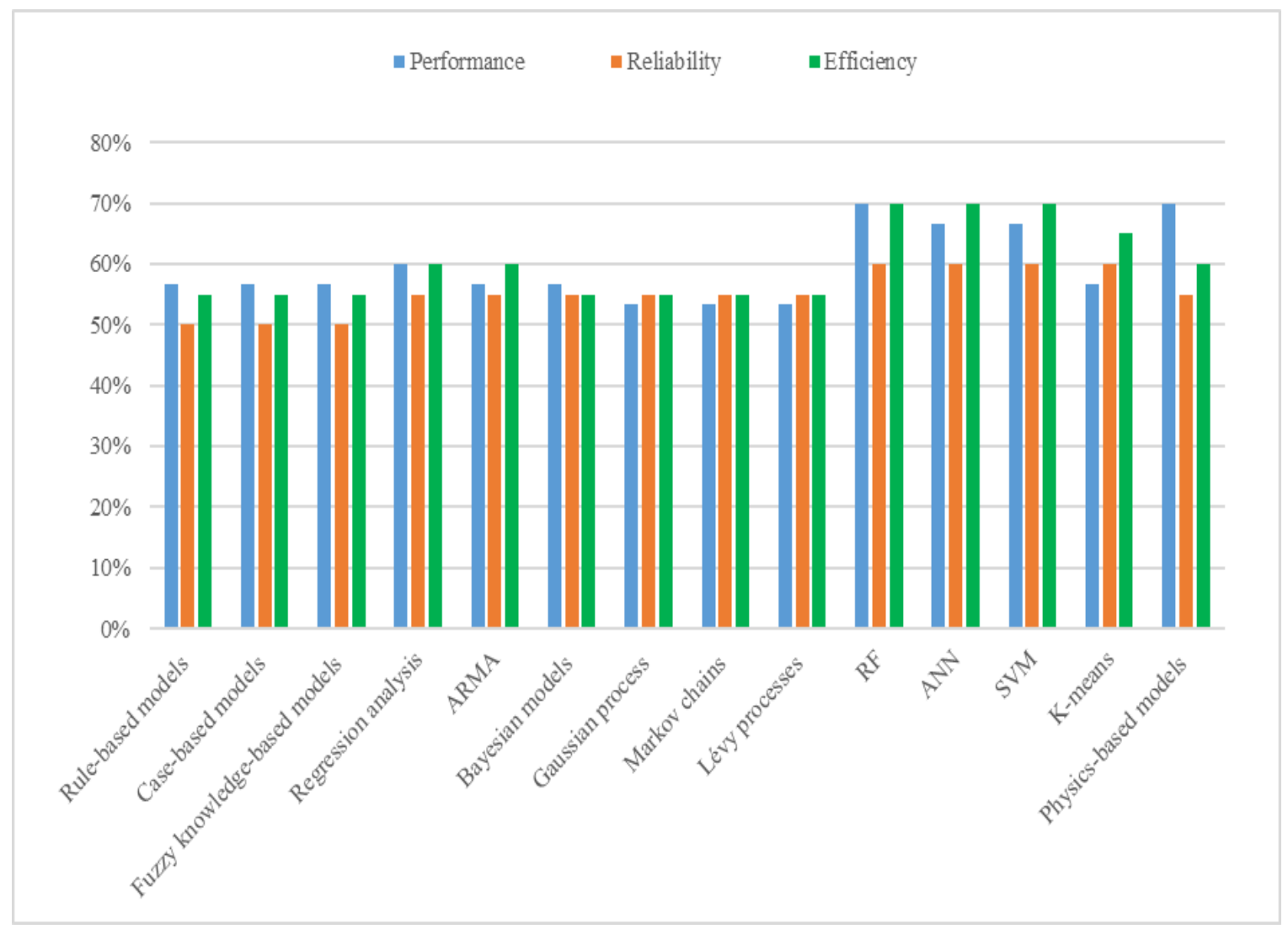

Figure 5 Comparison results of single-model approaches

While the comparative study of data analysis and processing approaches can be revealing for predictive maintenance, the ranking is less obvious if we take into account the digital transformation in the improvement of services and maintenance activities, namely Big Data, Internet of Things (IoT) and Artificial Intelligence. It is therefore difficult to compare these models in a meaningful way. Still, it's instructive to look at some trends, including the shift from knowledge-based models to data-driven machine learning models. Establishing a correlation between these different models and the factors taken into account is necessary in order to choose the appropriate model that is most suitable. All of the above comparison results are shown in Figure 5.

The analysis carried out on this graph reveals the following strengths:
- Machine learning models "RF, ANN, and SVM" and specifically RF (Random Forest) are more efficient and have extreme reliability and good efficiency. These models are able to process and capture complex relationships between data. The results obtained are more precise and more reliable in order to assess the deterioration and calculate the remaining useful life (RUL) of the equipment. The main challenges of these models are the management of the uncertainty related to the data, as well as the considerable time for the calculation;

- Physical models are more suited to integration for diagnostic or prognostic tasks in multi-model approaches with statistical, stochastic or ANN neural networks models. In return, they require great skills in mathematics and physics for their application; 


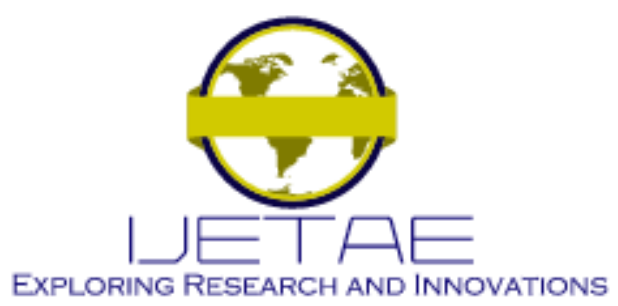

International Journal of Emerging Technology and Advanced Engineering

Website: www.ijetae.com (E-ISSN 2250-2459, Scopus Indexed, ISO 9001:2008 Certified Journal, Volume 11, Issue 10, October 2021)

- Statistical models "Regression analysis, ARMA, and Bayesian models" are used to identify / assess the deterioration of equipment, and to calculate the residual life of the system. For predictive systems, statistical models are often implemented as part of multi-model approaches;

- Models based on knowledge "Rule-based models, Case-based models, and Fuzzy knowledge-based models" are the first models implemented in early 1990 as part of predictive maintenance to perform diagnostics. These models are based on the experiences accumulated over long periods of system operation and maintenance. These constraints limit their use for forecasting tasks. These models require the use of data mining techniques to extract knowledge;

- Stochastic models "Gaussian process data, Markov chains, and Levy processes", are probability models evaluating the evolution of parameters due to their regression capacities. However, they need high computing power and the integration of complementary techniques or models to manage uncertainties.

\section{COMPARISON OF MUlTi-Model APPROACHeS}

The main criteria on which we base ourselves to compare the combinations of multi-model approaches are:
- Exploitation rate: this is the proportion of studies carried out using a multi-model approach compared to all the studies consulted;

- Possibility of processing heterogeneous data from databases and sensors;

- Effectiveness of the approach: this factor determines the ability of the combination to be more effective in terms of improving the accuracy of the result obtained from the assigned task (diagnosis, prognosis, management of uncertainties, and data exploration);

- Mutual cooperation between models of the combination: this criterion assesses the level of collaboration of the combined models to obtain results.

Figure 6 presents a comparison of multi-model approaches based on the above criteria and information gathered from various sources. The first score goes to multi-model approaches combining physical models with data-based models due to the mutual cooperation of databased models with the modelling efficiency of physical models. Second, the approach of combining data-driven models with knowledge-based ones, due to their ability to deal with more complex and heterogeneous data. In the last row, we find the knowledge-based multi-model approaches, due to their limitations for prognostics.

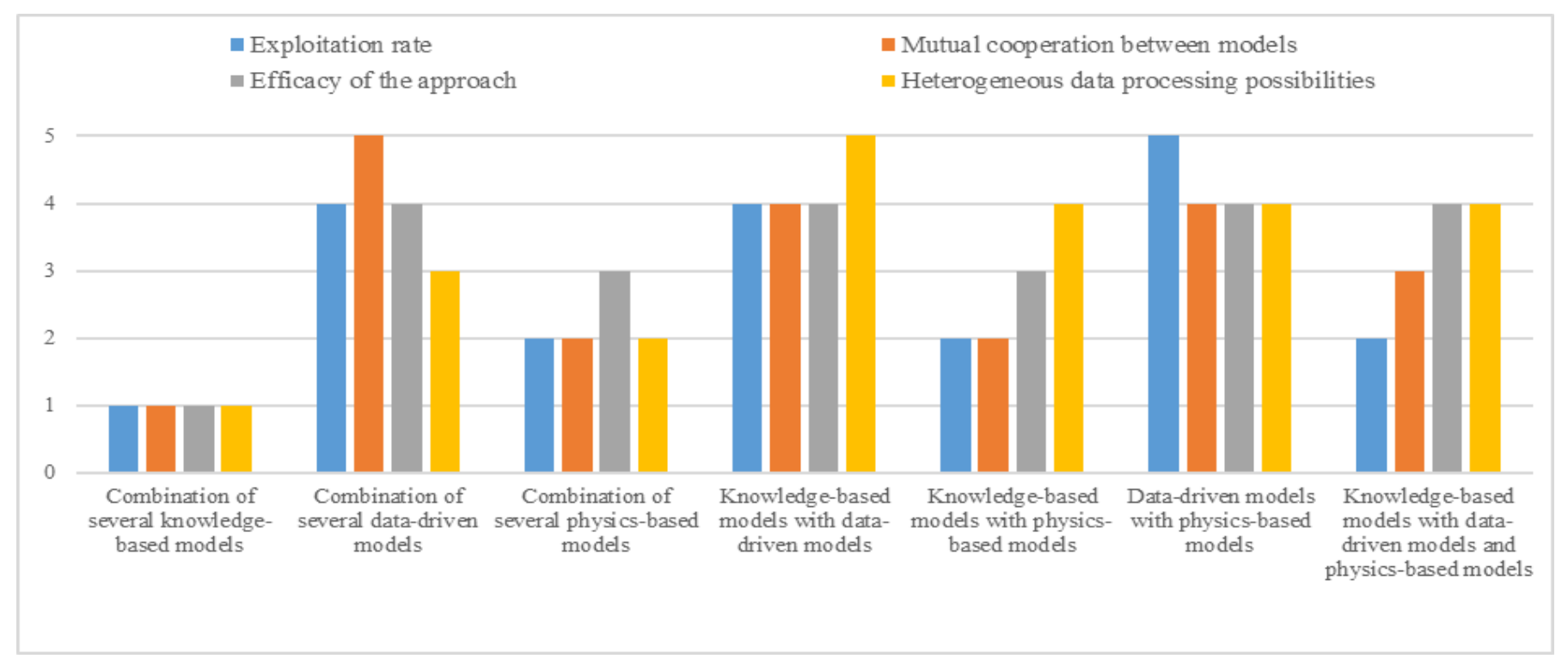

Figure 6 Comparison results of multi-model approaches 


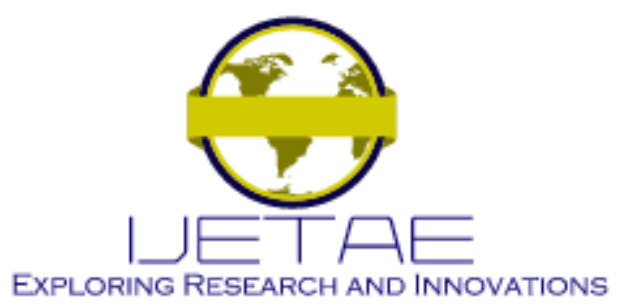

International Journal of Emerging Technology and Advanced Engineering

Website: www.ijetae.com (E-ISSN 2250-2459, Scopus Indexed, ISO 9001:2008 Certified Journal, Volume 11, Issue 10, October 2021)

\section{CONCLUSION AND DisCUSSION}

We have carried out several comparative studies involving the characteristics required of the data analysis and processing approaches for predictive maintenance. The main conclusions that we can draw from this study are as follows:

- The most suitable models in the context of current industrial digitization are data-driven machine learning models (RF, ANN, SVM, and k-means). The Random Forest "RF" algorithm is the most efficient of these;

- Knowledge-based models "Rule-based models, Casebased models, Models based on fuzzy knowledge" are based on experience and require the use of data mining methods to collect potential information, which limits them for prognostic tasks;

- Physics-based models are among the most efficient in modelling degradation;

- Stochastic models based on "Gaussian process data, Markov chains, Levy processes" are relatively efficient. They are more suited to integration for diagnostic or prognostic tasks in multi-model approaches to complex systems;

- The trends observed in research studies of the last decade lead to the use of multi-model approaches. The approach of combining physical models with datadriven models is most common due to the growing reputation of data-driven models and their complementarity with the modelling efficiency of physical models.

This article provides an overview for choosing an appropriate diagnostic and prognostic approach for predictive maintenance, it also shows that the choice of a model or the design of the topology of a multi-model approach is a complex issue that must be decided by taking into account the technological level of the technical system, and its operational context of external influence. This work is a comparative study based on the syntheses of different research studies in the field of predictive maintenance for the selection of a diagnostic and prognostic. To extend this work, research can be carried out on the extrapolation of current diagnostic and prognostic solutions to complex systems, and the difficulty of merging types of data sources.

\section{REFERENCES}

[1] J. J. Montero Jimenez, S. Schwartz, R. Vingerhoeds, B. Grabot and M. Salaün, "Towards multi-model approaches to predictive maintenance: A systematic literature survey on diagnostics and prognostics," Journal of Manufacturing Systems, 56, 539-557, 2020.

[2] E. Uhlmann, R. P. Pontes, C. Geisert, and E. Hohwieler, "Cluster identification of sensor data for predictive maintenance in a selective laser melting machine tool," Procedia manufacturing, 24, 60-65, 2018.

[3] A. Agnar, E. Plaza, "Case-Based reasoning: Foundational issues, methodological variations, and system approaches," AI Commun, 7, 39-59, 1994, https://doi.org/10. 3233/AIC-1994-7104.

[4] J.Z. Sikorska, M. Hodkiewicz, and L. Ma, "Prognostic modelling options for remaining useful life estimation by industry," Mech Syst Signal Process, 25, 1803-36, 2011, https://doi.org/10.1016/j.ymssp.2010.11.018.

[5] M.S. Haque, M.N. Bin Shaheed,S. Choi, "RUL estimation of power semiconductor switch using evolutionary time series prediction," IEEE Transp. Electrif. Conf. Expo, ITEC, 2018, https://doi.org/10.1109/ITEC.2018.8450131.

[6] D. Zhang, A.D. Bailey, D. Djurdjanovic, "Bayesian identification of hidden Markov models and their use for condition-based monitoring," IEEE Trans Reliab, 2016, https://doi.org/10.1109/TR.2016.2570561.

[7] M.S. Kan, A.C.C. Tan, J. Mathew, "A review on prognostic techniques for non-stationary and non-linear rotating systems," Mech Syst Signal Process, 62-63, 1-20, 2015, https://doi.org/10.1016/j.ymssp.2015.02.016.

[8] Z. Zhang, X. Si, C. Hu, Y. Lei, "Degradation data analysis and remaining useful life estimation: a review on Wiener-process-based methods," Eur J Oper Res, 271, 775-96, 2018, https://doi.org/10.1016/j.ejor.2018.02.033.

[9] T. P. Carvalho, F. A. A. M. N. Soares, R. Vita, R. da P. Francisco, J. P. Basto, S. G. S. Alcalá, "A systematic literature review of machine learning methods applied to predictive maintenance," Elsevier, 0360-8352, 2019, https://doi.org/10.1016/j.cie.2019.106024.

[10] V. Mathew, T. Toby, V. Singh, B. M. Rao, and M. G. Kumar, "Prediction of remaining useful lifetime (RUL) of turbofan engine using machine learning," IEEE International conference on circuits and systems (ICCS), 306-311, 2017.

[11] S. Biswal, and G. R. Sabareesh, "Design and development of a wind turbine test rig for condition monitoring studies," International Conference on Industrial Instrumentation and Control (ICIC), 891896, 2015.

[12] T. Huuhtanen, and A. Jung, "Predictive maintenance of photovoltaic panels via deep learning," IEEE Data Science Workshop (DSW), 66-70, 2018.

[13] T. Praveenkumar, M. Saimurugan, P. Krishnakumar, and K. I. Ramachandran, "Fault diagnosis of automobile gearbox based on machine learning techniques," Procedia Engineering, 97, 20922098, 2014. 


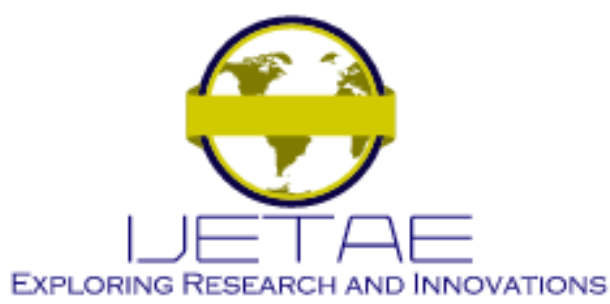

International Journal of Emerging Technology and Advanced Engineering

Website: www.ijetae.com (E-ISSN 2250-2459, Scopus Indexed, ISO 9001:2008 Certified Journal, Volume 11, Issue 10, October 2021)

[14] H. Li, D. Parikh, Q. He, B. Qian, Z. Li, D. Fang, and A. Hampapur, "Improving rail network velocity: A machine learning approach to predictive maintenance," Transportation Research Part C: Emerging Technologies, 45, 17-26, 2014.

[15] A. Downey, Y. H. Lui , C. Hu, S. Laflamme, S. Hu, "Physics-based prognostics of lithiumion battery using non-linear least squares with dynamic bounds," Reliab Eng Syst Saf, 182, 1-12, 2019.

[16] P. P. Ruiz, B. K. Foguem, B. Grabot, "Generating knowledge in maintenance from Experience Feedback," Knowl-Based Syst, 68, 420, 2014, https://doi.org/10.1016/j.knosys.2014.02.002.

[17] D. C. Swanson, "A general prognostic tracking algorithm for predictive maintenance" IEEE Aerosp. Conf. Proc, 2001, https://doi.org/10.1109/aero.2001.931317.
[18] P. Wang, B.D. Youn, C. Hu,"A generic probabilistic framework for structural health prognostics and uncertainty management," Mech Syst Signal Process, 28, 622-37, 2012, https://doi.org/10.1016/j.ymssp.2011.10.019.

[19] J. Chiachío, M. Chiachío, D. Prescott, J. Andrews, “A knowledgebased prognostics framework for railway track geometry degradation," Reliab Eng Syst Saf, 181, 127-41, 2018, https://doi.org/10.1016/j.ress.2018.07.004.

[20] A. M. Riad, H. K. Elminir, H. M. Elattar, "Evaluation of neural networks in the subject of prognostics as compared to linear regression model," Int J Eng Technol, 10, 52-8, 2010. 